\title{
MICROWAVE PYROLYSIS OF BIOMASS: Control of process parameters for high pyrolysis oil yields and enhanced oil quality.
}

\author{
John Robinson ${ }^{\mathrm{a}}$, Chris Dodds ${ }^{\mathrm{a}}$, Alexander Stavrinides ${ }^{\mathrm{a}}$, Sam Kingman ${ }^{\mathrm{a}}$, Juliano Katrib ${ }^{\mathrm{a}}$, Zhiheng $\mathrm{Wu}^{\mathrm{b}}$, Jose \\ Medrano $^{\mathrm{b}}$, Ralph Overend ${ }^{\mathrm{b}}$ \\ ${ }^{a}$ Energy \& Sustainability Research Division, Faculty of Engineering, University of Nottingham. NG7 2RD. \\ UK \\ ${ }^{\mathrm{b}}$ Future Blends Limited, Didcot, Oxfordshire. OX14 4SA. UK
}

\begin{abstract}
The oil yield and quality of pyrolysis oil from microwave heating of biomass was established by studying the behaviour of Larch in microwave processing. This is the first study in biomass pyrolysis to use a microwave processing technique and methodology that is fundamentally scalable, from which the basis of design for a continuous processing system can be derived to maximise oil yield and quality. It is shown systematically that sample size is a vital parameter that has been overlooked by previous work in this field. When sample size is controlled the liquid product yield is comparable to conventional pyrolysis, and can be achieved at an energy input of around $600 \mathrm{kWh} / \mathrm{t}$. The quality of the liquid product is significantly improved compared to conventional pyrolysis processes, which results from the very rapid heating and quenching that can be achieved with microwave processing. The yields of Levoglucosan and phenolic compounds were found to be an order of magnitude higher in microwave pyrolysis when compared with conventional fast pyrolysis. Geometry is a key consideration for the development of a process at scale, and the opportunities and challenges for scale-up are discussed within this paper.
\end{abstract}

\section{Introduction}

The motivation for finding sustainable hydrocarbon alternatives to fossil fuels in energy production and platform chemicals has stimulated a high demand for energy efficient conversion technologies for biomass. One of these technologies is fast pyrolysis, a process which subjects relatively dry biomass to a rapid rate of heat up, short residence times at $500 \pm 50^{\circ} \mathrm{C}$, followed by a rapid quench to ambient conditions. The product is typically $65-70 \%$ mass of a liquid product, and approximately equal amounts of permanent gases and a solid char. The liquid product can be further upgraded by hydrodeoxygenation to hydrocarbon fuels, or used directly as a fuel in thermal applications [1]. The requirement to rapidly heat biomass, such as wood to high temperatures is challenging as these materials are thermal insulators, which limits the capability of conventional heating techniques.

Development of the coupled thermal, mass transfer and chemical kinetics involved in fast pyrolysis was initially undertaken in the 1980s [2]. More recent studies, such as the work of Koufopanos et al. [3], have established that the chemical kinetics consist of two parallel pathways: a low activation energy pathway producing primarily gas and char; and a high activation energy path producing condensable vapours and minor quantities of char and gas. The former pathway is the classical route to produce char in long duration kilns, while the second pathway is now known as flash pyrolysis. To reach the high activation energy pathway without the penalty of the regular char production requires that the biomass be heated rapidly to the point where the high activation energy is overcome, and the liquid product pathway becomes the primary reaction. 
In conventional pyrolysis energy is transferred to the biomass primarily by conduction, from the external particle surface to the core. The particle surfaces are heated by a combination of conduction and convection. This presents a significant challenge for bulk materials such as biomass as heat transfer through the bulk is governed by conduction through individual particles, with very limited convective heat transfer within the voids. The limitations of conventional heat transfer result in slow heating rates within large particles, and consequently processing equipment with a very large volume and footprint in order to yield the necessary residence time. Improvements in conductive heat transfer can be made by reducing the size of the biomass particles to increase the surface area to mass ratio, however this requires a series of size reduction steps and results in entrainment of the

solid fraction with the liquid and gaseous products from the pyrolysis process, and the need for further downstream separation steps $[4,5,6]$. Fluidised bed processes can be used to enhance the convective component of heat transfer, however this concept requires extremely tight control over the particle size and extensive separation, gas handling and energy recovery systems. With conventional heating any gains in heat transfer are offset by the need for more peripheral equipment, and inevitably a much higher capital cost. Other approaches to achieve high heat fluxes include ablative contact heating and auger (screw) pyrolysis processes [7,8].

The fundamental heat transfer limitations remain the primary reason why conventional pyrolysis is not yet a mainstream technology for bio-energy and bio-derived products. Clearly any new technology that can match or better the quality of biomass derivatives from conventional processing whilst simplifying the system flowsheet is highly desirable, and it is here that there are significant opportunities for microwave heating.

\section{Microwave Pyrolysis - A volumetric heating approach}

In contrast to conventional heat transfer, microwaves heat volumetrically due to the presence of an electric field within the process material. Microwave heating is a thermal process, therefore the energy requirements are fundamentally the same as conventional heating provided that the same decomposition chemistry occurs with each approach. Significant benefits to heating using microwaves have been shown across a wide range of chemical decomposition and synthesis applications [9], specifically due to the overcoming of heat transfer limitations. In pyrolysis microwave heating may offer a number of potential advantages over conventional heating:

- Instantaneous volumetric heating, overcoming heat transfer constraints with significantly reduced equipment size

- Pyrolysis of larger particles without the need for size reduction and downstream separation $[6,10,11]$

- Minimal need for inert sweep gas

- Potential to produce a different range or grade of products due to the unique thermal gradients that result from microwave heating.

The potential advantages offered by microwave heating have resulted in several studies in this area. Current work in this field has been reviewed by Lam et al. [12] and Motasemi et al. [13]. Biomass has been shown to decompose through the use of microwave heating to produce liquid and gaseous fractions, with the relative yield of each fraction dependent upon the processing conditions and biomass used. Liquid yields of 30-60\% are widely reported for flash pyrolysis process where high intensity electric fields are used. Where previous research has shown that microwave pyrolysis is achievable, the majority 
of these studies have been carried out with off-the-shelf microwave equipment with poorly defined electric field distributions and a lack of reflected power measurement. Many studies use microwaveabsorbing additives such as silicon carbide or activated carbon to induce pyrolysis $[14,15]$, due to the low intensity electric fields supported by standard laboratory equipment and a lack of understanding of the dielectric properties of the process materials. The latter consideration is fundamentally important as the dielectric properties define the interaction of electromagnetic energy with biomass, and it is vital that these parameters are understood across the range of process temperatures to determine the most effective experimental configuration and to interpret the results obtained. The dielectric properties of biomass change significantly, and non-linearly with temperature [11]. Consequently the amount of applied power that is absorbed by the biomass will vary significantly during batch processing unless dynamic impedance-matching techniques are used, and energy calculations require integration of the absorbed power over time.

A large number of publications report the use of modified microwave ovens [16] or small scale laboratory based systems without supporting data to qualify the energy delivered to the pyrolysis sample $[17,18]$, so consequently no energy balance can be carried out. Where additives are used, these heat selectively compared to the biomass and result in localised temperatures $>1000^{\circ} \mathrm{C}$ even with relatively low power microwave equipment. In these cases there will be significant gasification within the process despite bulk temperature readings being within the pyrolysis temperature range (350$\left.500^{\circ} \mathrm{C}\right)$.

A further drawback with previous studies is temperature measurement. There are a number of techniques whereby spot-measurements of temperature can be made in a microwave environment, however these are point-measurements within a media with a significant temperature distribution. It has also been shown that the addition of a thermocouple causes a significant distortion to the electric field [19], so the readings obtained are partly an artefact of the presence of the thermocouple rather than the behaviour of the sample under study. There are no reliable ways to measure the temperature distribution during microwave heating, so any data interpretation must not rely directly on these measurements.

the outcomes of previous studies into microwave pyrolysis are clearly of benefit to the scientific community, and the purpose of this paper is not to cast doubt on previous findings in this regard. However the results obtained from previous studies are not fundamentally scalable, and do not therefore serve the needs of the industrial processing community. The focus of this study is to use an experimental approach to microwave processing with a controlled electric field and power distribution, to gain a better understanding of microwave pyrolysis and a comparison with conventional processing. The specific objectives of this study are:

- To understand the maximum oil yield that can be obtained using microwave heating, and how the degree of decomposition varies throughout the volume of the samples used for processing.

- To determine the quality of the bio-oil obtained and carry out a direct comparison with conventional pyrolysis based on energy input and product quality.

- To understand the energy requirements for the microwave pyrolysis process

- To identify opportunities and challenges for scale-up. 


\section{Materials and methods}

\section{Feedstock and sampling}

The feedstock used was European Larch (Larix decidua) woodchips ( $25 \mathrm{~mm}$ ) sourced from within the UK and supplied by Nottinghamshire eco-fuels. The plantation trees at 12 years were chipped on -site including bark at Roxton Woods (58.57 N, $0.24 \mathrm{E}$ ). The water mass fraction was 26.24\% (ASTM D4442). To study the influence of particle size the feedstock was sieved through 4 and $12 \mathrm{~mm}$ meshes. After sorting the size fractions were stored below $6^{\circ} \mathrm{C}$ in polyethylene bags.

\section{Microwave pyrolysis system}

The microwave system included a $6 \mathrm{~kW}$ microwave generator $(2.45 \mathrm{GHz})$, automatic three stub tuner for power analysis and impedance matching and waveguides for energy transfer to the applicator. A TM $\mathrm{TM}_{01 \mathrm{n}}$ applicator supporting power densities of the order of $10^{8} \mathrm{~W} / \mathrm{m}^{3}$ in the heated phase was used to pyrolyse the wood chips. Unlike commercially-available single mode applicators, this device was specifically designed to sustain a high intensity electric field whilst allowing high temperatures to be achieved. The applicator comprised of a reaction chamber, waveguide entry point, sliding short circuit, microwave transparent partition and multiple gas ports (see Figure 1 and [11] for dimensions). Pyrex and borosilicate reaction vessels ( 8 to $100 \mathrm{~cm}^{3}$ volume) were used to accommodate the biomass within the applicator. The sample was positioned at the base of the applicator in the region of highest electric field intensity. The sample width and depth were maintained below $50 \mathrm{~mm}$, which is less than one quarter of the penetration depth and ensured the electric field distribution within the sample was as even as possible. Nitrogen $(2 \mathrm{~L} / \mathrm{min}$ ) was used for purge and as a sweep gas to maintain an oxygen free atmosphere and aid the removal of process gases from within the applicator.

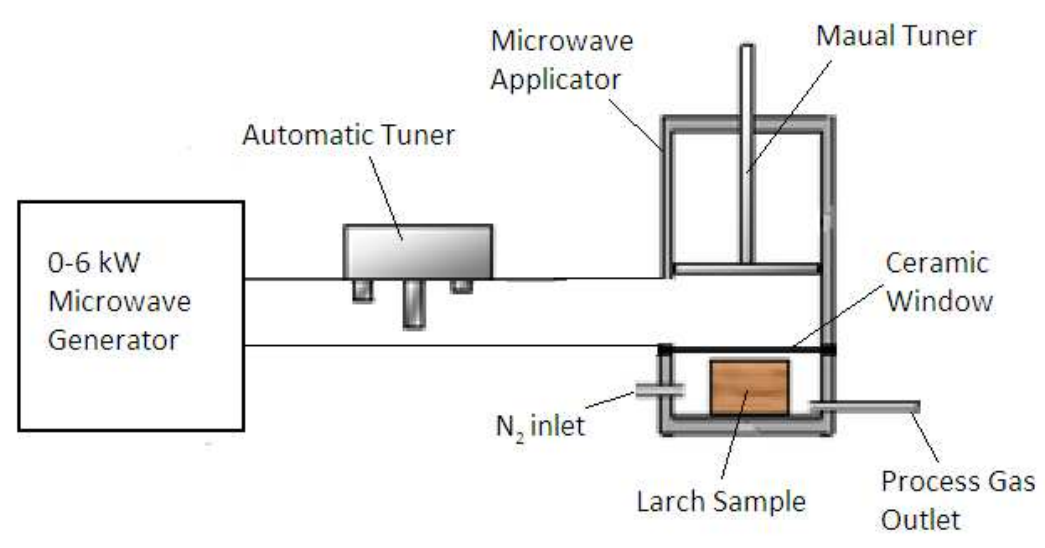

Figure 1 - Microwave Pyrolysis system

The exit port was coupled to three cryogenic cold traps to condense the pyrolysis products. A wire mesh was used within the traps to increase the surface area and subsequently the trapping efficiency. Gas samples were taken downstream of the condensation system. 
Experiments were carried out at powers of 1-6 kW for 12-216 seconds to give specific energy ranges from 150-4000 kWh/t depending on the mass, applied power and time selected. The sample mass was varied from $5-20 \mathrm{~g}$.

\section{Conventional Pyrolysis}

The Larch was shredded to $<4 \mathrm{~mm}$, and dried to a water mass fraction of $12 \%$ before being pyrolyzed in a $500 \mathrm{~g} / \mathrm{h}$ fluid bed operated at $500^{\circ} \mathrm{C}$, with a hot vapour filter at $450^{\circ} \mathrm{C}$ and a conventional recovery train for the produced pyrolysis oil. The fluid bed medium was Olivine, and the sweep gas was $\mathrm{N}_{2}$. The product oil yield on a wet basis was $57 \%$ of the mass of dry feedstock. The char yield was $14 \%$ and the gas yield $14.3 \%$. The mass balance closure was $92 \%$. The total organic liquid yield was $48.5 \%$ based on the mass of the dry feedstock.

\section{Analysis methods}

\section{Absorbed Power and Energy}

A six-port measurement technique [20] was used for power measurement and impedance matching. Forward and reflected power was logged, and the energy absorbed by the Larch sample obtained by integrating the absorbed power over the duration of each experiment. Temperature was not measured in this study due to the limitations of accurately measuring the temperature distribution within the bed of biomass during microwave heating.

\section{Product Yield}

The remaining volatiles in the solid mass were measured by Thermogravimetric Analysis (TGA) on a TA Instruments system (Q5000) using the method as described by Sauerbrunn et al. [21]. The distribution of decomposed biomass within the treated sample was determined by sampling across the height and radius of the sample and carrying out TGA analysis as described above. Condensable product was recovered from the condensation system and applicator surfaces by acetone washing, and acetone was subsequently removed by vacuum evaporation. Liquid product was also recovered by washing the solid residue.

\section{Product Quality}

Pyrolysis gas was sampled using a syringe from a gas bag downstream of the condensation system. The gaseous products were analysed by a Perkin Elmer system (Clarus $580 \mathrm{GC}$ ) with a thermal conductivity detector (TCD). The columns used were Rt Alumina Bond $/ \mathrm{KCl}(30 \mathrm{~m} \times 0.32 \mathrm{~mm}$ i.d., $5 \mu \mathrm{m})$ for the analysis of non-hydrocarbons, and a Haysep $\mathrm{N} 6$ packed column $\left(60-80,7^{\prime} \times 1 / 8^{\prime \prime}\right.$ sulfinert) for the analysis of hydrocarbons. The gas standard was a mixture of $\mathrm{H}_{2}, \mathrm{CH}_{4}, \mathrm{CO}, \mathrm{CO}_{2}, \mathrm{C}_{2} \mathrm{H}_{4}$ and $\mathrm{C}_{2} \mathrm{H}_{6}$. Dilution with pure argon was used for the production of calibration curves. Argon was used as the carrier gas.

Samples for volatile organic compound measurements (VOC) were prepared in 2-pentanone and a second set of samples were prepared in acetone for semivolatile (SVOC) analysis, by GC-MS. Two sets of $60 \mu \mathrm{g} / \mathrm{cm}^{3}$ samples were prepared in analytical reagent grade acetone (purchased from Fisher) and 2pentanone (Acros Organics) and both were characterised by gas chromatography-mass spectrometry (Agilent 7890A GC-MS). The injection unit temperature of the GC was $300^{\circ} \mathrm{C}$ and was coupled to a HPVOC column $(60 \mathrm{~m} \times 0.2 \mathrm{~mm}, 1.12 \mu \mathrm{m})$. The $\mathrm{GC}$ oven was heated from $45^{\circ} \mathrm{C}$ to $280^{\circ} \mathrm{C}$ at a rate of 3 
${ }^{\circ} \mathrm{C} / \mathrm{min}$ while the system was purged with helium carrier gas with a split ratio of 25 . Separated compounds were recorded with the Agilent $5975 \mathrm{C}$ mass selective detector with ionisation energy of 70 $\mathrm{eV}$ and a scanning range of $\mathrm{m} / \mathrm{z} 30-550$ in the full scan mode.

For qualitative and quantitative analysis, reagent grade standards were purchased (isoeugenol, eugenol, creosol, guaiacol, phenol, furfural, catechol and levoglucosan from Sigma Aldrich and hydroxyacetone from Acros Organics) and prepared in acetone. A second set of calibration standard was prepared in 2pentanone for more volatile compounds like acetic acid, acetone and methanol (purchased from Acros Organics). The calibration standards were prepared in the concentration range of $200-1000 \mu \mathrm{g} / \mathrm{cm}^{3}$ and analysed using the same method as for the fuel samples.

\section{Results and Discussion}

\section{Dielectric Properties}

The dielectric properties of Larch were measured using the cavity perturbation technique described by Lester et al. [22], and loss tangent data is shown in Figure 2.

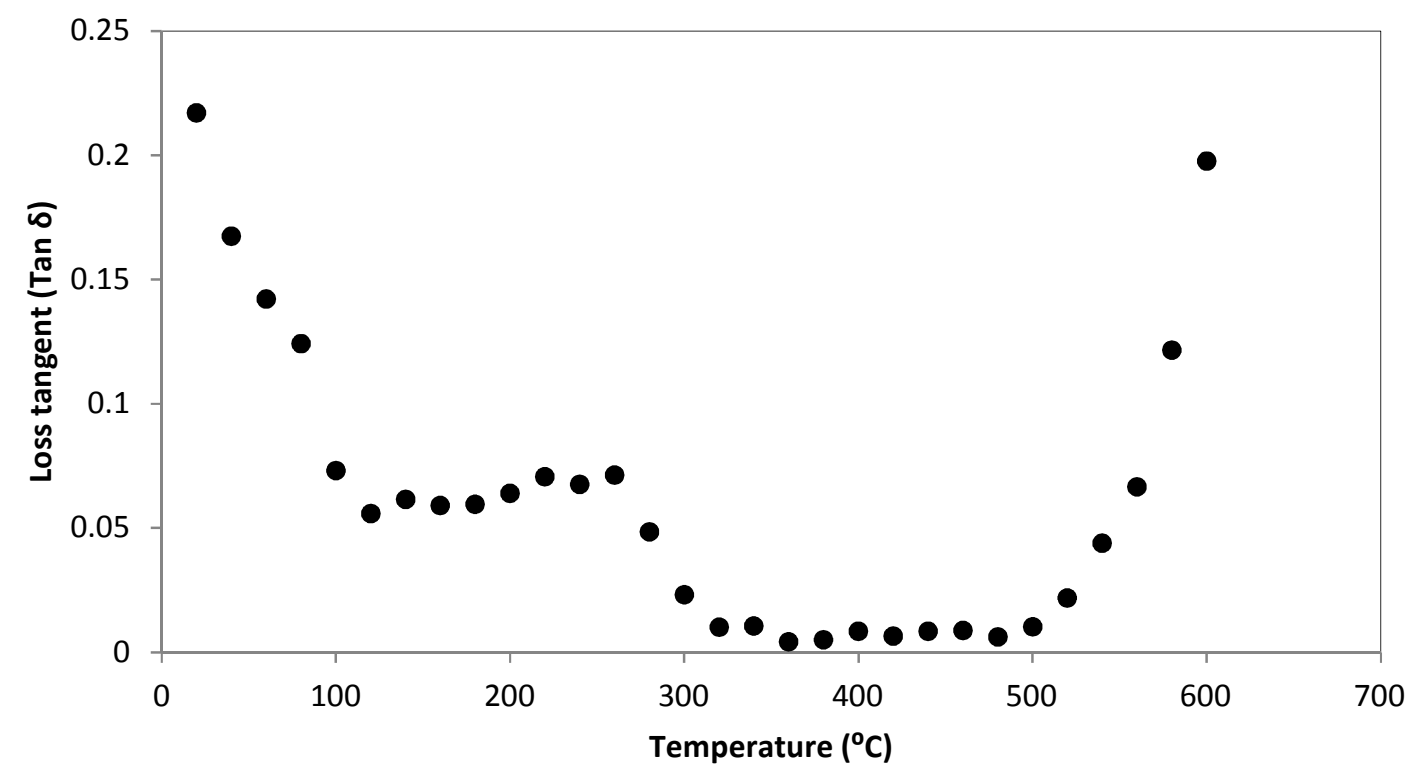

Figure 2 - Loss Tangent of Larch at $2.45 \mathrm{GHz}$, as a function of temperature.

The loss tangent defines the relative degree to which a material will be heated during interaction with electromagnetic energy, with higher values indicating more power absorption and hence more heating. Figure 2 shows that the loss tangent varies non-linearly with temperature. At room temperature the Larch used for this study has a loss tangent of 0.22 , which decreases as the temperature approaches $100^{\circ} \mathrm{C}$. This drop in loss tangent will cause more of the microwave power to be reflected, and corresponds to the decrease in absorbed power after 20 seconds in Figure 2. At temperatures above $100^{\circ} \mathrm{C}$ there is still an appreciable loss tangent, which ranges from $0.05-0.07$ from $100-250^{\circ} \mathrm{C}$. Larch will still absorb microwaves within this temperature range, although not to the same extent as at room temperature. From $250-350^{\circ} \mathrm{C}$ the loss tangent decreases significantly, and remains very low up to $480^{\circ} \mathrm{C}$. Very little power will be absorbed over this temperature range, and this accounts for the fact that 
many previous studies have used microwave-absorbing additives when attempting microwave pyrolysis in low-power, off the shelf laboratory equipment. At temperatures above $500^{\circ} \mathrm{C}$ there is a significant increase in the loss tangent, corresponding to carbonisation of the Larch. The carbonaceous residue is a strong microwave absorber as it has a significant conductive component to the loss mechanism [22].

There are many potential explanations as to the exact physio-chemical transformations taking place during this period, however these are not within the scope of this report. For pyrolysis to occur temperatures of up to $450^{\circ} \mathrm{C}$ are required. The primary interpretation from Figure 2 is that if the temperature exceeds $500^{\circ} \mathrm{C}$ then carbonisation occurs, leading to an increase in the loss tangent, more power absorbed and consequently much higher temperatures attained. In this case significant gasification will occur rather than pyrolysis. For a pyrolysis process using microwave heating it is imperative that the samples are treated such that temperatures in excess $0 f 500^{\circ} \mathrm{C}$ are not achieved. Where previous studies have used microwave-absorbing additives it is impossible to control the temperature within the sample to avoid reaching $500^{\circ} \mathrm{C}$, as the localised temperature around the additives is likely to be $>1000^{\circ} \mathrm{C}$. Liquid yield and product quality data from these studies is therefore compromised as there is significant gasification taking place, so previous results are a net effect of pyrolysis and gasification rather than pyrolysis alone.

\section{Liquid yield}

For a microwave process to give comparable results to conventional processing then liquid yields of the order of $50-60 \%$ need to be achieved. In this study the liquid yield was found to vary significantly with treatment conditions. The absorbed power, processing time and sample mass can all be reconciled by the energy absorbed per unit mass. This is an alternative, and more reliable approach than temperature measurement in order to reconcile the data and identify the key governing parameters. Energy absorbed allows a direct comparison of the entire experimental matrix, and the complete data-set is shown in Figure 3. The effect of individual variables is shown subsequently in Figures $4-6$. 


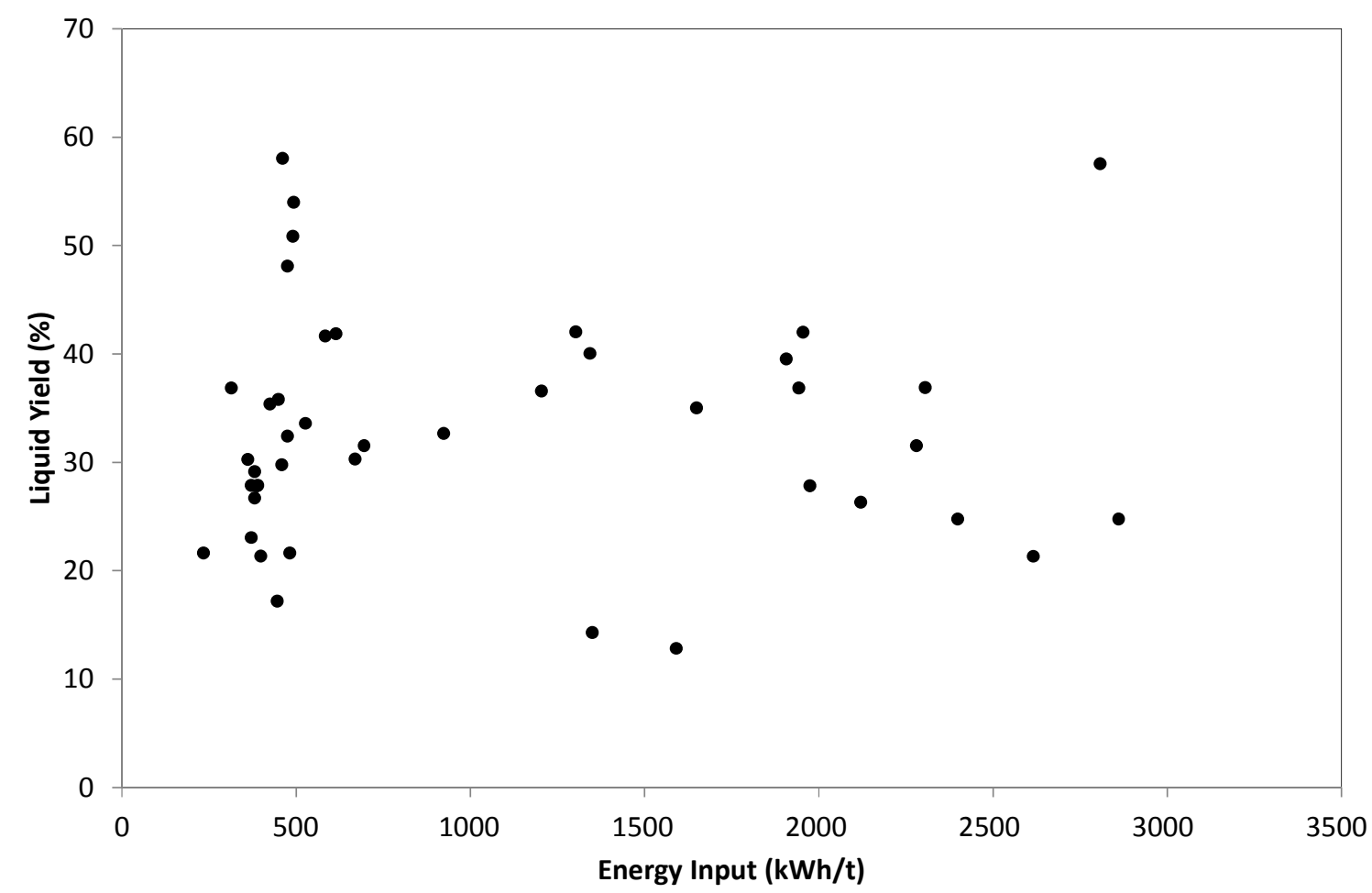

Figure 3 - Range of liquid yields achieved during this study at various combinations of power, mass and time; plotted against energy input.

Across the range of experiments conducted the average liquid yield was $41 \%$. From the variability seen in Figure 3, absorbed energy is clearly not the single parameter that defines liquid yield. At $500 \mathrm{kWh} / \mathrm{t}$ $(1.8 \mathrm{~kJ} / \mathrm{g})$ the liquid yield varies from $15-57 \%$, so it is therefore possible to achieve a variable liquid yield by varying the power, heating time or sample mass at an equivalent energy input. This behaviour has been shown previously in a small number of studies on non-biomass systems [23,24]. Separate and systematic investigations of power, heating time and sample mass are therefore required to further understand the dominant parameter that affects liquid yield, and therefore determine how yield can be optimised. The variation in liquid yield with power and time at equivalent energy inputs are shown in Figures 4 and 5.

Variation with Applied Power and Heating Time 


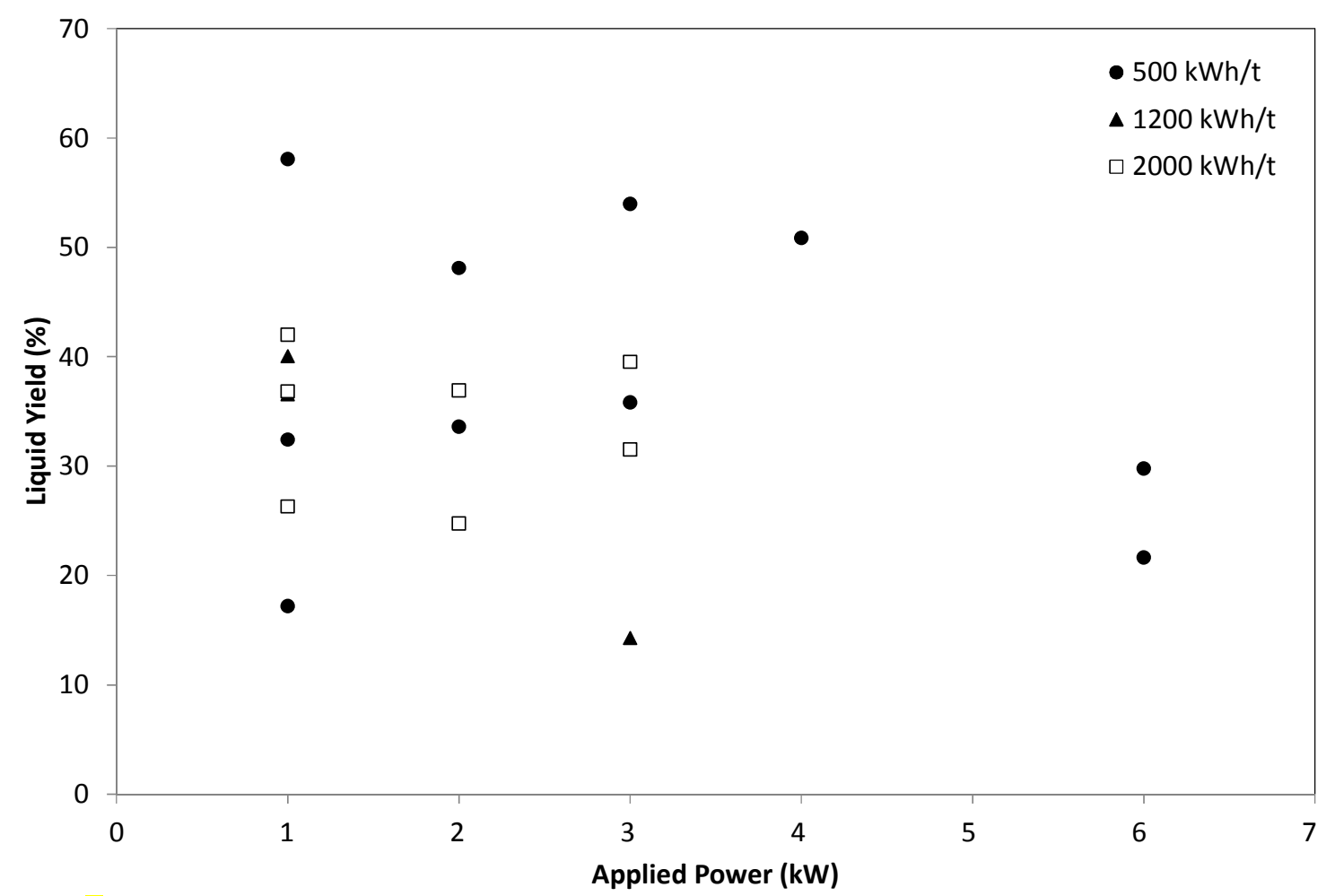

Figure 4- Liquid yield versus power input at 500, 1200 and $2000 \mathrm{kWh} / \mathrm{t}$ and sample size of 20g.

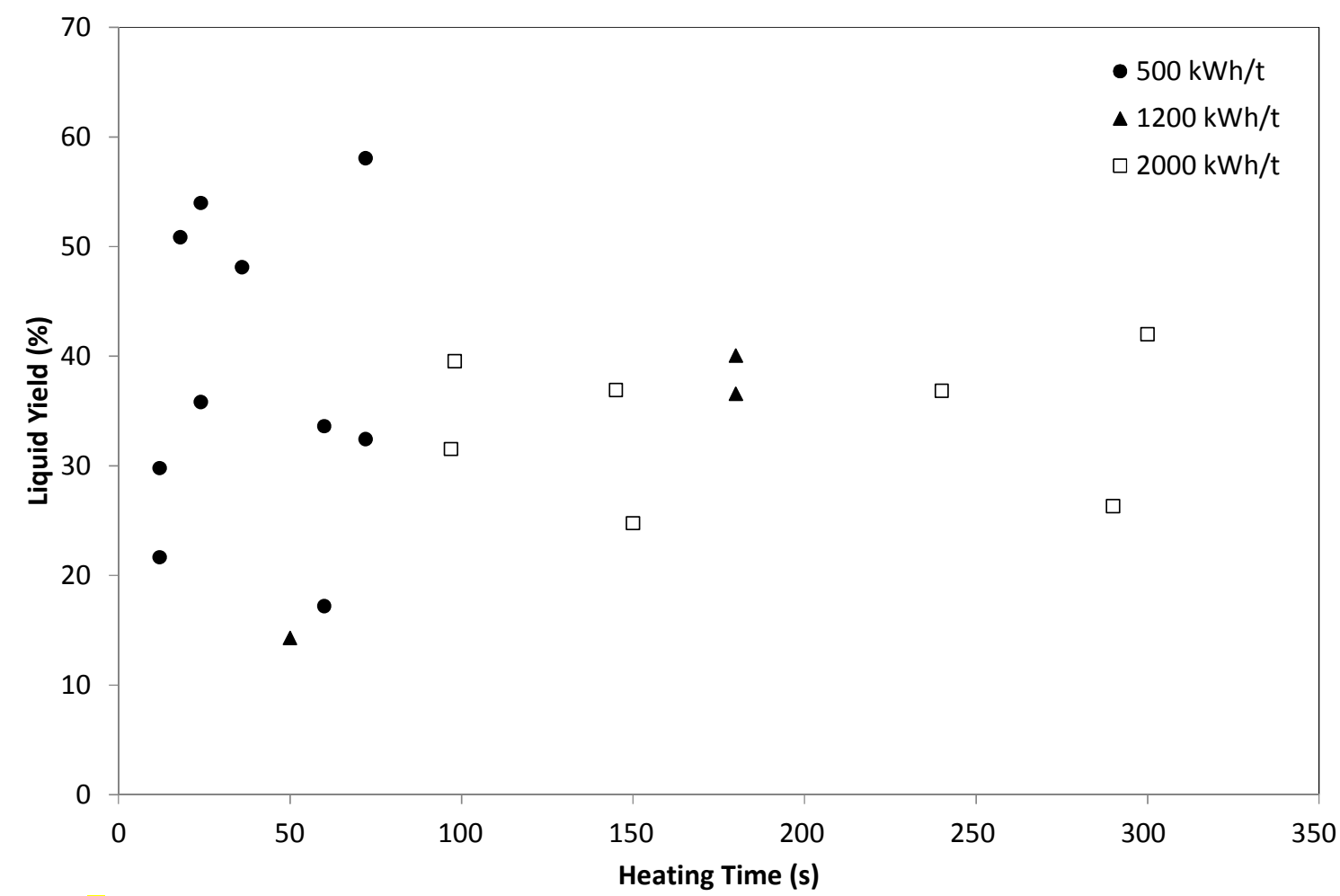

Figure 5 - Liquid yield versus heating time at 500, 1200 and $2000 \mathrm{kWh} / \mathrm{t}$ and sample size of $20 \mathrm{~g}$. 
Figures $4 \& 5$ show that there is no distinct correlation between either power or heating time, even when compared at equivalent energy input. Unlike previous studies into microwave processing of biomass, this study quantified the energy absorbed using a six-port measurement technique, and therefore a rigorous energy balance was subsequently carried out. As a result the variation in liquid yield shown in Figures 3-5 is inherent to the pyrolysis process, and not an artefact of the experimental or measurement techniques employed. To further understand the reasons for this variability the effect of sample size was studied.

\section{Variation with Sample Mass}

The sample mass was studied in two discrete increments at 5 and 20g. The liquid yield measurements on $5 \mathrm{~g}$ samples were not reproducible enough to be reported due to the very low liquid mass collected in a large volume, and subsequent errors when concentrating a very small amount of liquid during solventwashing. To allow the data to be compared across the range of sample sizes studied the amount of solid volatilised was used as the measured variable rather than liquid yield, as this can be measured to within $+/-0.5 \%$ for small samples. The reflected power was higher for the lower sample masses, so comparing on the basis of applied power or treatment time is not valid in this case. Experiments were carried out using $5 \mathrm{~g}$ and $20 \mathrm{~g}$ samples at $500 \mathrm{kWh} / \mathrm{t}$, conditions that yield an average of $43 \%$ volatilised. 8 separate experiments were carried out on the $5 \mathrm{~g}$ samples, and 14 experiments on $20 \mathrm{~g}$ samples, and the variability of solid volatilised during these experiments is shown in Figure 6.

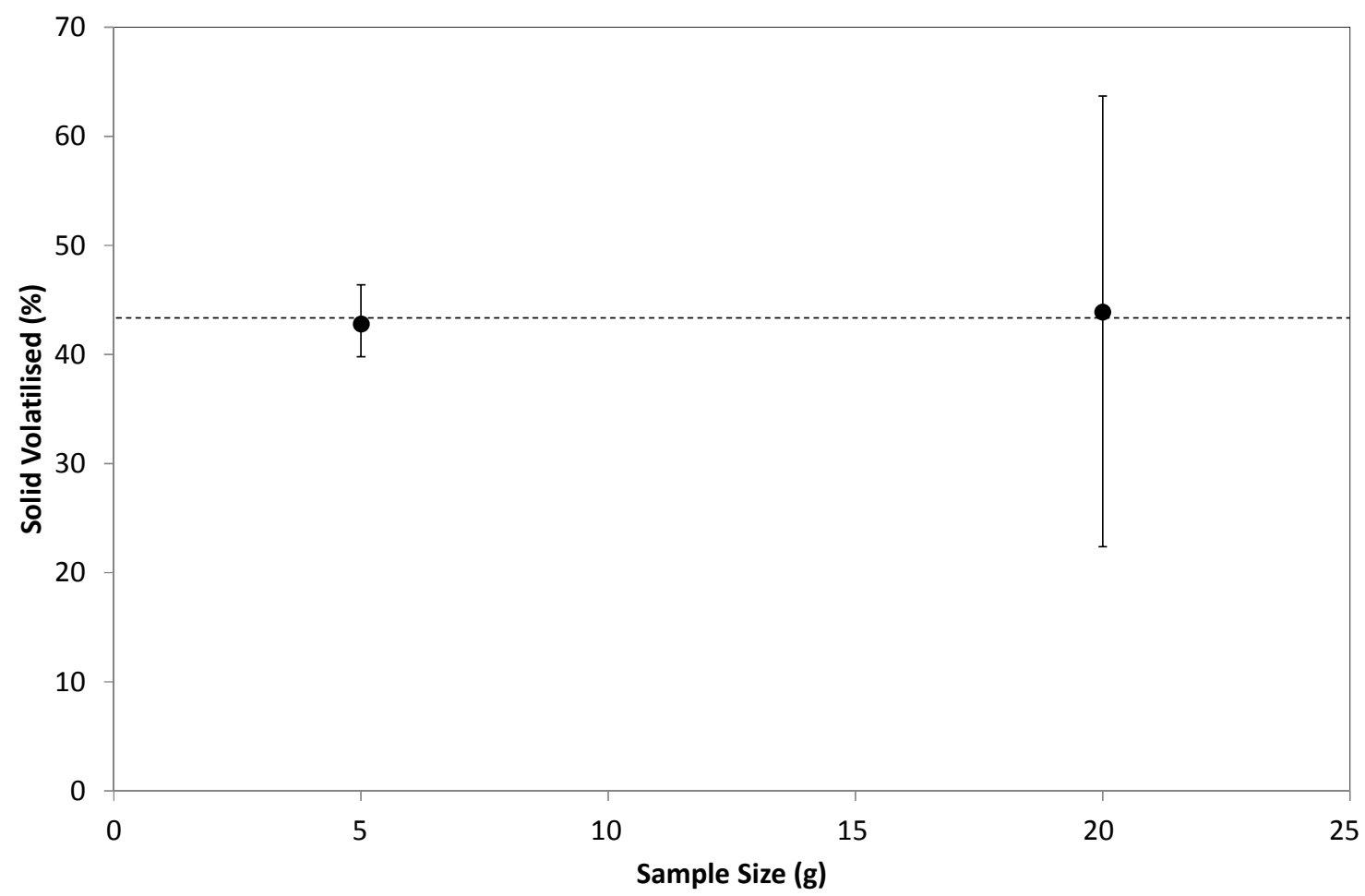

Figure 6 - Variability of solid volatilised for $5 \mathrm{~g}$ and $20 \mathrm{~g}$ samples sizes at $500 \mathrm{kWh} / \mathrm{t}$. Error bars denote maximum and minimum values.

For the $5 \mathrm{~g}$ samples the solid volatilised varied from $39.8-46.4 \%$, with a standard deviation of 2.77 . In contrast, the solid volatilised from $20 \mathrm{~g}$ samples varied from $22.4-63.1 \%$, and a standard deviation of 
11.70. Pyrolysis of $5 \mathrm{~g}$ samples is therefore more reproducible than $20 \mathrm{~g}$ samples. $5 \mathrm{~g}$ samples were subsequently pyrolysed at a range of energy inputs, and this data is shown in Figure 7.

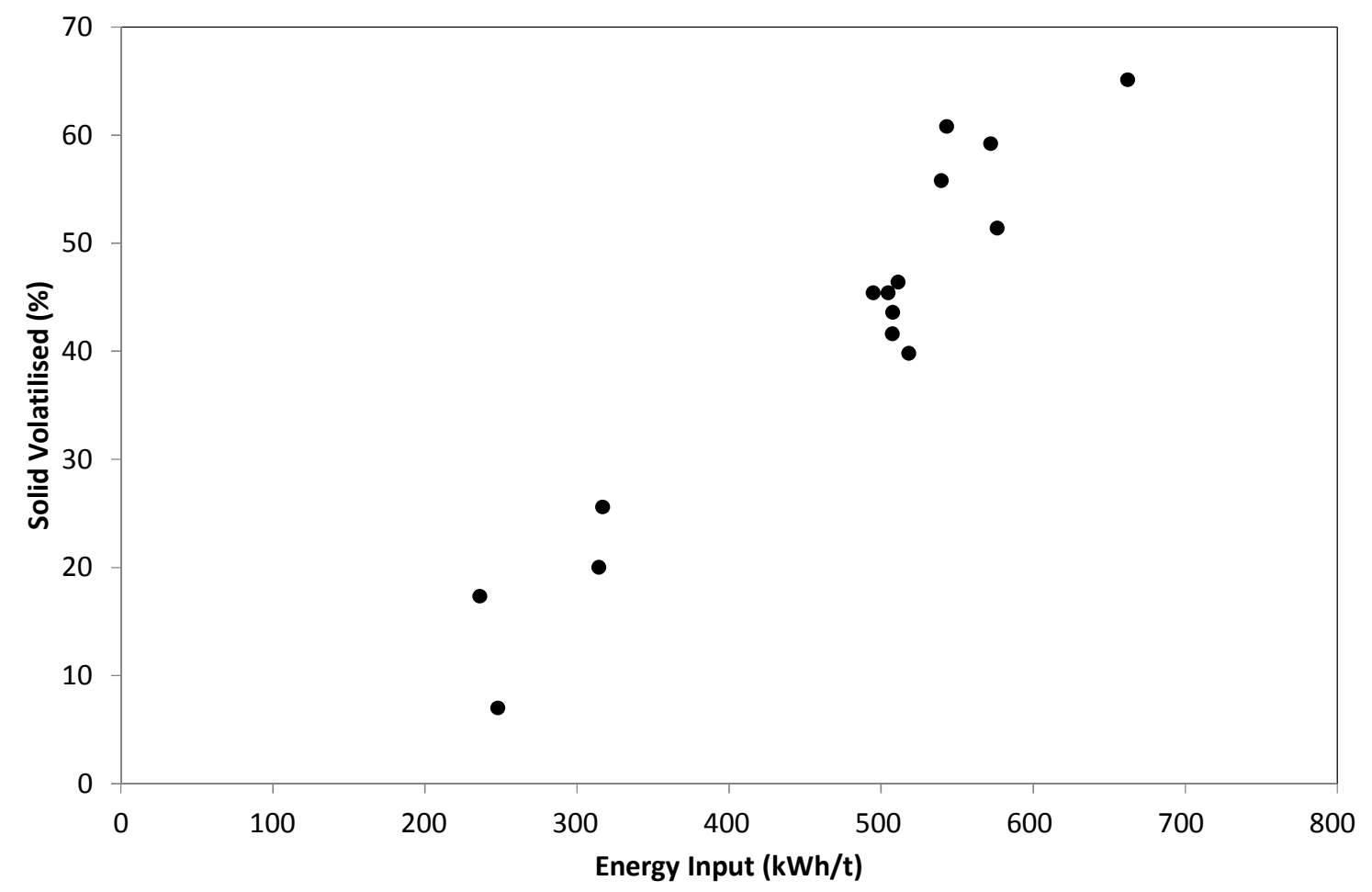

Figure 7-Solid volatilised versus energy input for a sample size of $5 \mathrm{~g}$.

When the sample size is reduced to $5 \mathrm{~g}$ a clear trend emerges in Figure 7 of increasing solid volatilised with increasing energy input, a trend which is not apparent for the $20 \mathrm{~g}$ samples shown in Figure 4. Energy inputs of $600-700 \mathrm{kWh} / \mathrm{t}(2.2-2.5 \mathrm{~kJ} / \mathrm{g})$ are required to pyrolyse $60-70 \%$ of the solid, a level that is comparable with conventional pyrolysis. Improvements in energy efficiency of $20-30 \%$ are likely with a continuous system due to the limitations of batch processing [23].

The likely explanation for the difference in behaviour between $5 \mathrm{~g}$ and $20 \mathrm{~g}$ samples is that the heating is more uniform within the smaller sample. The $5 \mathrm{~g}$ samples had a diameter of $15 \mathrm{~mm}$, compared with $50 \mathrm{~mm}$ for $20 \mathrm{~g}$ samples. The electric field strength varies throughout the bulk of the sample due to the applicator geometry and due to attenuation as the microwaves are absorbed by the biomass. In an empty applicator the peak electric field occurs along the central axis, and given the relatively low dielectric constant of bulk biomass [11] the peak is likely to occur towards the centre of the sample during processing. The volumetric heating is therefore non-uniform throughout the sample, which will be exaggerated with larger sample sizes. Larger samples also suffer from conventional heat transfer limitations. As heat is absorbed volumetrically it is lost from the sample by conduction and convection. The core of larger samples is likely to be well insulated, meaning that a significant temperature gradient can exist throughout a large sample. Carbonisation could occur within the central core of a large sample, with minimal decomposition of the biomass at around the circumference. Coupled electromagnetic and 3D heat transfer models would be required to test this hypothesis theoretically, however an empirical method can also be used by measuring the extent to which decomposition has taken place at different locations within a single sample. 


\section{Heterogeneity}

Visual observations of the $20 \mathrm{~g}$ biomass samples after treatment all clearly showed the effects of a nonhomogeneous treatment. Material beds showed much darker areas where near complete pyrolysis had occurred with a treatment gradient to the edges where material had partially volatilised. Figure 8 shows a representative image of untreated biomass and that treated after microwave heating. Of note is that the visually untreated section occurs closest to the waveguide inlet to the applicator. This heterogeneous treatment is typical of volumetric heating, as previously shown by Miura et. al. [25].
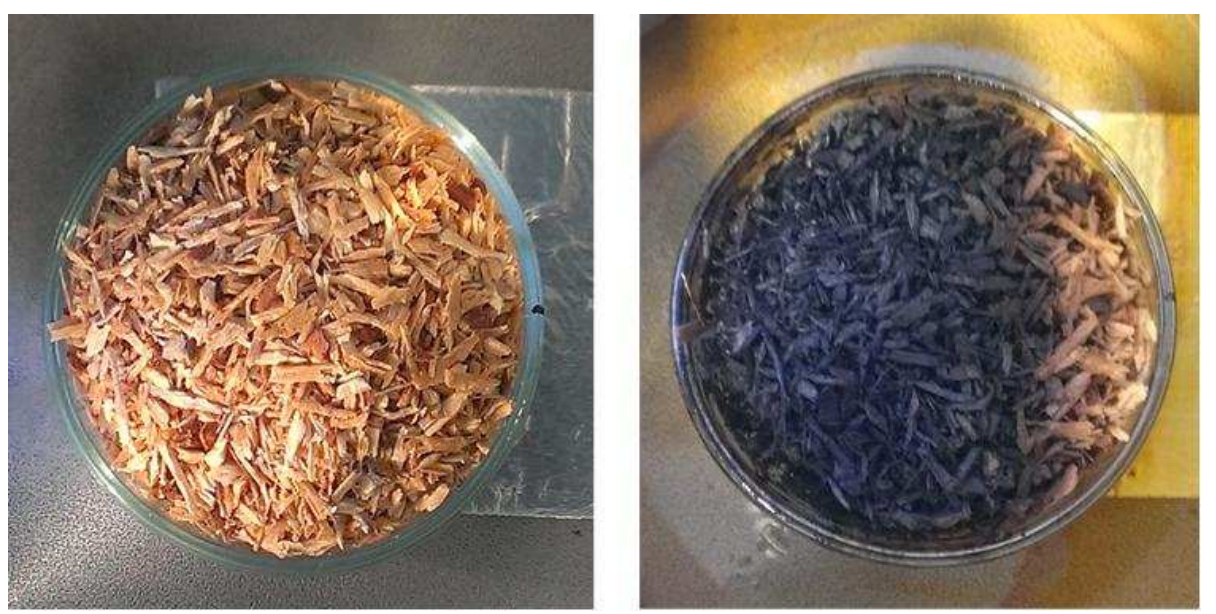

Figure 8 - Images of $20 \mathrm{~g}$ untreated sample (left) and sample treated at $1 \mathrm{~kW}$ and $500 \mathrm{kWh} / \mathrm{t}$ (right)

Treated biomass from a $20 \mathrm{~g}$ sample with $46 \%$ volatilised was selected for analysis. A total of 18 samples were taken from 9 locations across the plane of the dish at two depths (surface and mid bed depth) for TGA analysis, with an additional untreated sample used for referencing. Mass loss at $550^{\circ} \mathrm{C}$ was used to determine remaining VOC compared to conventional pyrolysis. This data is shown in Figure 9, along with an illustration of sub-sample location.
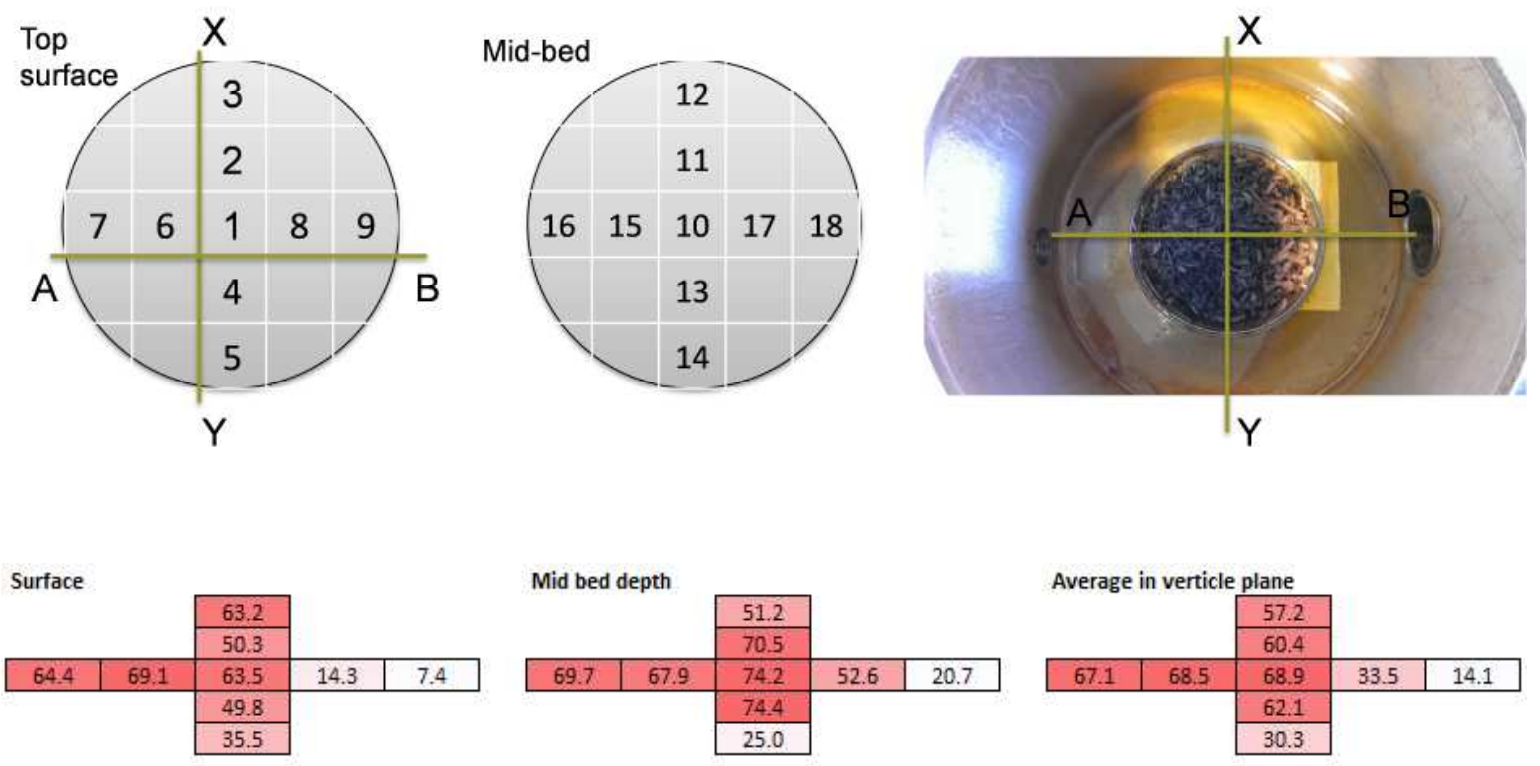
Figure 9 - Solid volatilised (\%) with location within the bulk sample. Bulk volatilisation $=46 \%$
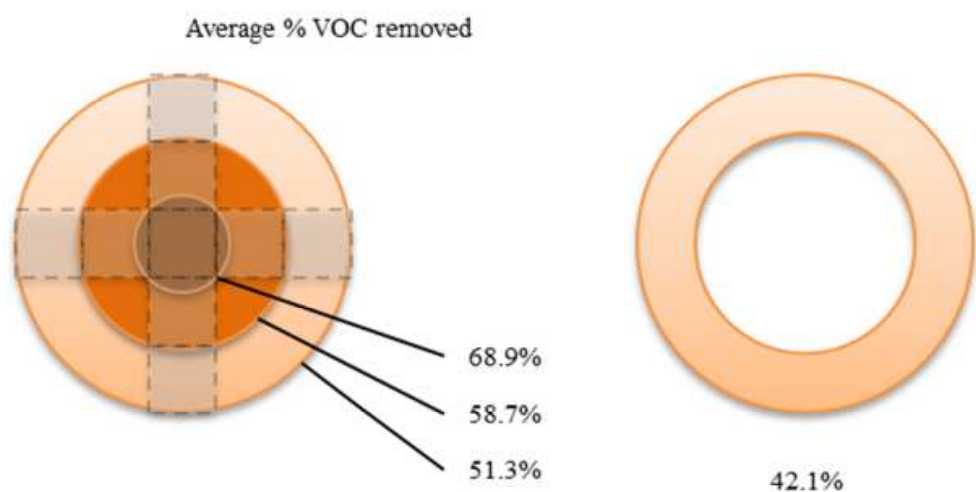

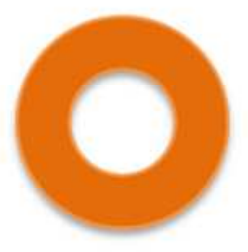

$56.1 \%$

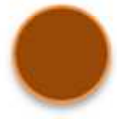

$68.9 \%$

Figure 10 - Average volatilisation in three radial sections within the sample. Central core diameter = $12 \mathrm{~mm}$. Bulk volatilisation $=46 \%$

The data shown in Figures 9 and 10 confirms the visual observations in Figure 8, and supports the hypothesis that treatment is heterogeneous. The highest degree of volatilisation occurs within the centre of the sample, with up to $75 \%$ volatilised, and much less treatment towards the edges. The degree of volatilisation of the bulk sample and hence the liquid yield is therefore an average, which accounts for the liquid yields of $30-40 \%$ with the $20 \mathrm{~g}$ sample. It is not possible to increase the bulk liquid yields for $20 \mathrm{~g}$ samples because carbonisation starts to occur within the central core, which increases the loss tangent (Figure 2) and results in more power being dissipated within this zone rather than the untreated regions of the sample. This phenomena, known as thermal runaway, is well documented for microwave processes that utilise materials whose loss tangent increases with temperature [26].

When lower sample sizes are used the non-uniformity is less pronounced, the treatment is more even and the average liquid yield is higher, in this case $69 \%$ compared to the bulk average of $54 \%$. Experiments were conducted on $2 \mathrm{~g}$ samples with the same geometry as the central 'core' shown in Figure 9. Processing such small samples in batch tests is challenging as the reflected power levels are very high $(>75 \%)$, so establishing a consistent energy basis for comparison leads to a large standard deviation in the results obtained. For energy inputs of $500+/-80 \mathrm{kWh} / \mathrm{t}$ the observed solid volatilised was $66+/-11 \%$, which is consistent with the value of $68.9 \%$ shown in Figures 8 \& 9 .

This study has shown that liquid yields and the extent of volatilisation achieved with microwave processing are comparable with conventional processing, and can be achieved consistently when the sample size is of the order of $5 \mathrm{~g}$. This is a significant limitation for batch microwave processing, and means that any attempt to scale up must be continuous in order to accommodate this geometric limitation. A significant factor that will influence scale up is the quality of the products obtained from the microwave pyrolysis process, and this must be considered before the full implications for scale up are understood.

\section{Product Quality}


Liquid product was recovered from the condensers and traps, however there was a significant amount of condensate within the reactor. This is to be expected given that no hot gases were used for heating and the maximum duration of an experiment was three minutes. Some of the condensate was present on the surface of the processed biomass, so the reactor and remaining solids were washed with Acetone to remove the liquids prior to analysis. The amount of acetone was quantified and accounted for during calculation of the composition of the liquid fraction.

There are numerous constituents to bio-oils, however this study focusses on the standard compounds whose presence and relative abundance is indicative of the chemistry of the transformations taking place, and those that can be used to give a comparison with conventional pyrolysis processes. Acid Number (TAN), Elemental Analysis, Water Content, SVOC and SOV analyses were used to characterise oil quality.

\begin{tabular}{|c|c|}
\hline \multicolumn{2}{|c|}{ Total Acid Number (TAN) } \\
\hline $\begin{array}{c}\text { Conventional } \\
\text { Pyrolysis }\end{array}$ & $\begin{array}{c}\text { Microwave } \\
\text { Pyrolysis }\end{array}$ \\
\hline $80-200$ & $56-190$ \\
\hline
\end{tabular}

Table 1 - TAN values for conventional and microwave pyrolysis

Table 1 shows the TAN values of the oils obtained from conventional pyrolysis $[27,28,29]$ and from the microwave pyrolysis carried out in this study. It is difficult to ascertain differences in the chemistry of the liquid products for TAN values above 30 , and bio-oils that can be used without refinement need to have TAN values $<5$. The key conclusion from Table 1 is that the TAN values for the liquid fraction from microwave pyrolysis are the same as those from conventional pyrolysis.

Table 2 shows the elemental (CHN) composition for the organic phase, along with the water content, whilst Table 3 shows the concentration of specific components within the hydrocarbon phase.

\begin{tabular}{|l|c|c|}
\hline \multirow{2}{*}{ Substance } & $\begin{array}{c}\text { Conventional } \\
\text { Pyrolysis }\end{array}$ & $\begin{array}{c}\text { Microwave } \\
\text { Pyrolysis }\end{array}$ \\
\cline { 2 - 3 } & weight \% & weight \% \\
\hline $\mathrm{C}$ & 33.4 & 40.8 \\
\hline $\mathrm{H}$ & 8.3 & 7.8 \\
\hline $\mathrm{N}$ & $<0.5$ & 0.5 \\
\hline Water & 32 & 27 \\
\hline
\end{tabular}

Table 2 - Elemental analysis of the hydrocarbon phase, and water content 


\begin{tabular}{|l|c|c|}
\hline \multirow{2}{*}{ Substance } & $\begin{array}{c}\text { Conventional } \\
\text { Pyrolysis }\end{array}$ & $\begin{array}{c}\text { Microwave } \\
\text { Pyrolysis }\end{array}$ \\
\cline { 2 - 3 } Levoglucosan & $\mathrm{g} / \mathrm{kg}$ & $\mathrm{g} / \mathrm{kg}$ \\
\hline Acetic acid & 4.49 & 52.42 \\
\hline Formic acid & 24.00 & 28.32 \\
\hline Furfural & 0.59 & 13.18 \\
\hline Methanol & 6.07 & 7.22 \\
\hline Creosol & 0.51 & 5.06 \\
\hline Guaiacol & 0.53 & 4.52 \\
\hline Isoeugenol(trans) & 0.49 & 4.49 \\
\hline Catechol & 0.70 & 3.36 \\
\hline Eugenol & 0.40 & 4.16 \\
\hline Phenol & 0.47 & 1.42 \\
\hline Methyl formate & $<0.5$ & 0.82 \\
\hline
\end{tabular}

Table 3 - Analysis of volatile and semi-volatile organic compounds in the liquid product.

The analysis for volatile organic compounds - both volatile and semivolatile showed essentially the same fingerprint with respect to the organic compounds. Only those compounds above the minimum detectable limit are shown in Table 3. It is clear that microwave pyrolysis results in a much larger abundance of semi-volatile compounds than conventional pyrolysis. For example, Levoglucosan yields are an order of magnitude higher with microwave pyrolysis. Methanol and Acetic acid are present at comparable levels, which imply that the primary pyrolysis mechanism and product chemistry is the same for both microwave and conventional pyrolysis. The higher abundance of Levoglucosan and other semivolatile compounds indicates that there is much less secondary degradation in the microwave process than in the conventional equivalent. This is to be expected given that microwave heating is carried out in the presence of a cold sweep gas and with very low thermal inertia, so the evolved pyrolysis products are subsequently cooled and condensed very rapidly. The cooler process environment preserves much larger amounts of fragile compounds, especially those from carbohydrate breakdown such as levoglucosan, formic acid, and furfural. Similarly the light phenolics (creosol, guaiacol, isoeugenol and catechol) are in much higher concentrations than the condensates from the conventional fast pyrolysis, where the filter and quench system maintain the pyrolysis products at a much higher temperature than the microwave process, and for a longer time.

Bio-oil upgrading is carried out to mitigate much of the secondary degradation that occurs with conventional pyrolysis. The microwave product clearly has a lower molecular weight than the thermal pyrolysis oil and there is a marked increase in the mass fraction of monomeric sugar derivatives and of the phenolics, which offers alternative and more value added upgrading not only to fuels but also to platform chemicals. The conventional fluidised bed used olivine as a stationary media, which is known to 
exhibit some degree of catalytic upgrading. There was no catalyst present in the microwave pyrolysis experiments, so a direct comparison with conventional fluidised beds is likely to yield a larger improvement in product quality than that reported in this study.

\section{Analysis of the gas phase}

Gas samples were taken at the outlet of the condensate traps. GC analysis was carried out to assess the composition of the gas phase, and this data is shown in Table 4, along with comparative data for conventional pyrolysis of the same feedstock.

\begin{tabular}{|l|c|c|}
\hline \multirow{2}{*}{ Substance } & $\begin{array}{c}\text { Conventional } \\
\text { Pyrolysis }\end{array}$ & $\begin{array}{c}\text { Microwave } \\
\text { Pyrolysis }\end{array}$ \\
\cline { 2 - 3 } & vol\% & vol\% \\
\hline $\mathrm{CO}$ & 44.16 & 28.94 \\
\hline $\mathrm{CO}_{2}$ & 38.13 & 52.36 \\
\hline $\mathrm{H}_{2}$ & 5.63 & 5.59 \\
\hline $\mathrm{CH}_{4}$ & 8.44 & 6.75 \\
\hline $\mathrm{C}_{2} \mathrm{H}_{4}$ & 1.33 & 2.04 \\
\hline $\mathrm{C}_{2} \mathrm{H}_{6}$ & 1.16 & 2.52 \\
\hline $\mathrm{C}_{3} \mathrm{H}_{6}$ & 1.04 & 1.79 \\
\hline
\end{tabular}

Table 4-GC analysis of the evolved gas phase from Microwave and Conventional Pyrolysis

The $\mathrm{H}_{2}$ and hydrocarbon levels are comparable between the two heating approaches. This is to be expected given that the conditions in each system are maintained in order to maximise liquid yield, and the production of permanent gases is minor in both cases. Of note is the change in $\mathrm{CO} / \mathrm{CO}_{2}$ ratio from 1.16 in conventional pyrolysis to 0.55 in microwave pyrolysis. This may be an artefact of the lower bulk gas temperatures in the microwave pyrolysis system and their influence on the Water Gas Shift reaction, however further investigation is required to confirm this and is beyond the scope of this paper.

\section{Implications for Scale-up}

Scale-up of microwave processes should focus on and optimise the benefits of the technology over conventional processing techniques. This work has shown that there is no difference in the yield but a significant improvement in the quality of the liquid product formed from microwave pyrolysis compared with conventional fast-pyrolysis processes. The advantage of microwave heating is therefore the ability to produce higher value bio-oils, and with a process flowsheet that is simplified significantly compared to conventional methods. A cold sweep gas is required for immediate quenching of the pyrolysis products, a configuration that is not possible in conventional processes. There is no requirement for a fluidised bed as there are no heat-transfer limitations, so further advantages arise from the lack of hot gas handling and energy recovery units. The capital cost of microwave hardware is of the order of f1000-2000 per kW of installed power, much higher than conventional heating equipment. However, there is likely to be significantly less capital expenditure required on other plant within the system and 
lower operator/labour requirements given the reduced number of unit operations. There is also potential to process on a smaller scale, or even mobile processing systems when microwave heating is used due to the inherent low footprint of the process. A detailed economic analysis is therefore required to carry out a comparison of the two technologies at process engineering system level and for a number of scales.

If an economic analysis is favourable then the data shown in Figures 2, 8 and 9 present a key challenge to scale-up. For pyrolysis the temperature must be maintained below $500^{\circ} \mathrm{C}$, otherwise thermal runaway will occur and result in gasification rather than pyrolysis. For this reason the use of microwave absorbing additives will never be viable for pyrolysis of biomass on an industrial scale. Batch processing is not a viable option for microwave heating due to the variation in dielectric properties and absorbed power as the process proceeds, and due to the sample size constraint, so any microwave pyrolysis process must be continuous.

This study has shown the importance of sample size, which translates to reactor size and geometry when considering scale-up. Reactor geometries as small as $50 \mathrm{~mm}$ are not viable due to the heterogeneous nature of the heating due to both the distribution of the electric field and conventional heat transfer. Using large reactors will result in significant charring/gasification within some areas of the process material and almost zero treatment within others. Biomass must therefore be transported and processed within a narrow geometry in order to promote homogeneous treatment, only then can the liquid yields be comparable with conventional pyrolysis processes. The process must be capable of choking the microwaves to ensure compliance with Health \& Safety and EMC legislation, and materials and hardware must be capable of withstanding normal operating temperatures up to $500^{\circ} \mathrm{C}$, and potentially peak temperatures of over $1000^{\circ} \mathrm{C}$ if thermal runaway occurs.

Continuous transport and processing of biomass presents challenges for bulk materials handling, electromagnetic engineering and process engineering. Scaling up a microwave process for biomass pyrolysis is therefore a multidisciplinary challenge. There are many potential solutions that fit within the constraints outlined in this paper, and future work will identify options for scale up and demonstrate the benefits of microwave pyrolysis in a fully continuous system.

\section{Conclusions}

This study has established the technical feasibility of microwave pyrolysis of biomass to produce liquid bio-oil. Sample size has a significant influence on the process and products obtained, and is a parameter that has been overlooked by the vast majority of previous studies in this field. This work has shown that significant overheating can occur when the sample size is too large, of the order of $50 \mathrm{~mm}$. When sample sizes are kept within $15 \mathrm{~mm}$ then the degree of volatilisation of the feedstock can be consistently as high as $70 \%$, which is comparable with conventional pyrolysis processes. The quality of bio-oils produced is significantly higher than conventional heating methods, with order of magnitude increases in the abundance of Levoglucosan and phenolic compounds. Microwave processing is shown to have a significant advantage in using a cold sweep gas, and consequently does not require the use of a fluidised bed, hot gas handling and energy recovery systems. The future scale-up of a microwave pyrolysis process must utilise a continuous process, the design of which will be based on the geometric limitation established in this study. 


\section{Acknowledgements}

The authors wish to acknowledge Jenya Khvatsky, the late David Penfold, the Carbon Trust and UK's Department for Energy and Climate Change (DECC) for funding.

\section{References}

1 A.V. Bridgwater, Biomass and Bioenergy, 38, (2012) 68

2 Diebold J. Editor. Specialists' Workshop on the Fast Pyrolysis of Biomass Proceedings. Specialists' Workshop on the Fast Pyrolysis of Biomass; 19-22 October 1980; Copper Mountain, CO. Golden, CO, USA: Solar Energy Research Institute. 1980. 405 pp. Report No. SERI/CP - 622-1096.

3 Koufopanos CA, Papayannakos N, Machio G, Lucchesi A. The modelling of the pyrolysis of biomass particles. Studies on kinetics, thermal and heat transfer effects. Can J. Chem Eng 1991; 69(4):907-15

4 M.S. Mettler, D.G. Vlachos and P.J. Dauenhauer, Energy \& Environmental Science, 5, (2012) 7797.

5 J.E. White, W.J. Catallo and B.L. Legendre, Journal of Analytical and Applied Pyrolysis, 91, (2011) 1

6 G. van Rossum, B.M. Güell, R.P.B. Ramachandran, K. Seshan, L. Lefferts, W.P.M. Van Swaaij and S.R.A. Kersten, AIChE Journal, 56, (2010) 2200

7 M.J. Antal, Jr. and G. Varhegyi, Industrial \& Engineering Chemistry Research, 34, (1995) 703

8 A. Broido and M. Weinstein, Kinetics of solid-phase cellulose pyrolysis, at: 3rd International Conference of Thermal Analysis, Basel, 285.

9 C. Gabriel, S. Gabriel, E. H. Grant, B. S. J. Halstead and D. Michael P. Mingos, Chemical Society Reviews, 27, (1998) 213

10 C. Yin, Bioresource Technology, 120, (2012) 273

11 J.P. Robinson, S.W. Kingman, R. Barranco, C.E. Snape and H. Al-Sayegh, Industrial \& Engineering Chemistry Research, 49, (2010) 459.

12 S.S. Lam and H.A. Chase, Energies, 5, (2012) 4209

13 F. Motasemi and M.T. Afzal, Renewable and Sustainable Energy Reviews, 28, (2013) 317

14 Fernanda Cabral Borges, Zhenyi Du, Qinglong Xie, Jorge Otávio Trierweiler, Yanling Cheng, Yiqin Wan, Yuhuan Liu, Rongbi Zhu, Xiangyang Lin, Paul Chen, Roger Ruan. Fast microwave assisted pyrolysis of biomass using microwave absorbent. Bioresource Technology 156 (2014) 267-274

15 Arshad Adam Salemaa, You K. Yeow, Kashif Ishaque, Farid Nasir Anid, Muhammad T. Afzala, Azman Hassan. Dielectric properties and microwave heating of oil palm biomass and biochar. Industrial Crops and Products 50 (2013) 366- 374

16 Arshad Adam Salema, Farid Nasir Ani. Microwave induced pyrolysis of oil palm biomass. Bioresource Technology 102 (2011) 3388-3395

17 Quan Bu, Hanwu Le, Shoujie Ren, Lu Wang, Qin Zhang, Juming Tang, Roger Ruan. Production of phenols and biofuels by catalytic microwave pyrolysis of lignocellulosic biomass. Bioresource Technology 108 (2012) 274-279

18 Chunfei Wu, Vitaliy L. Budarin, Mark J. Gronnow, Mario De Bruyn, Jude A. Onwudili, James H. Clark, Paul T. Williams. Conventional and microwave-assisted pyrolysis of biomass under different heating rates. Journal of Analytical and Applied Pyrolysis 107 (2014) 276-283

19 John Robinson, Sam Kingman, Derek Irvine, Peter Licence, Alastair Smith, Georgios Dimitrakis, David Obermayer and C. Oliver Kappe. Phys. Chem. Chem. Phys., 2010, 12, 4750-4758

20 V. Bilik, Six-port Measurement Technique: Principles, Impact, Applications, at: Invited paper at the International Conference RADIOELEKTRONIKA

21 S. Sauerbrunn, P. Gill and T. Instruments, American Laboratory, 26, (1994) 29

22 Lester, E., Kingman, S., Dodds, C., Patrick, J. 2006 Fuel 85 (14-15) 2057-2063 
23 Robinson, J.P., Kingman, S.W., Snape, C.E., Bradley, M.S.A., Bradshaw, S.M. (2009) Chemical Engineering Journal 152 (2-3) 458-463

24 Robinson, J.P., Kingman, S.W., Snape, C.E., Barranco, R., Saeid, A. 2009 Separation and Purification Technology 69 (3), pp. 249-254

25 M. Miura, H. Kaga, A. Sakurai, T. Kakuchi and K. Takahashi, Journal of Analytical and Applied Pyrolysis, 71, (2004) 187.

26 R.J. Meredith. Engineers Handbook of Industrial Microwave Heating. IEEE, London 1998

27 Oasmaa, A., D.C. Elliott, and S. Müller, Quality control in fast pyrolysis bio-oil production and use. Environmental Progress \& Sustainable Energy, 2009. 28(3): p. 404-409

28 Oasmaa, A., D.C. Elliott, and J. Korhonen, Acidity of Biomass Fast Pyrolysis Bio-oils. Energy \& Fuels, 2010. 24(12): p. 6548-6554

29 Agblevor, F.A., et al., Production of Stable Biomass Pyrolysis Oils Using Fractional Catalytic Pyrolysis. Energy \& Fuels, 2010. 24(7): p. 4087-4089 